\title{
IMPLICAÇÕES DO PROLONGAMENTO DO PERÍODO DE JEJUM PERIOPERATÓRIO
}

\section{IMPLICATIONS OF EXTENDING THE PERIOPERATIVE FASTING PERIOD}

\section{Isis Rocha Bezerra ${ }^{1} *$ Aline Oliveira da Costa e Silva ${ }^{2} *$ Aryane da Silva Pires $^{3}$ Carlos $^{2}$ Eduardo Peres Sampaio 4}

O jejum perioperatório é uma prática adotada para evitar a broncoaspiração do conteúdo gástrico ingerido. ${ }^{1}$ Contudo um jejum prolongado acarreta na demora da recuperação pósoperatória, resposta metabólica debilitada, aumento da ansiedade e sensações intensas de sede e fome, que levam à desidratação e fraqueza. ${ }^{1,2,3}$ Assim, estas consequências aumentam o tempo de recuperação ao trauma cirúrgico e diminuem a capacidade fisiológica normal de responder a ele.

Uma das consequências do prolongamento do período de jejum perioperatório prolongado, é a resistência insulínica nos primeiros dias após a cirurgia, provocada pela diminuição dos níveis de insulina, seguida do aumento de glucagon, ativando a glicogenólise; juntamente devido à baixa disponibilidade de insulina e à consequente má absorção de glicose. ${ }^{1,3,4}$ Quando o período de jejum estende-se excessivamente, chegando perto de 24 horas, o organismo ativa o processo de gliconeogênese. ${ }^{3}$ Assim, o estado metabólico de resistência pode durar até três semanas após a realização do procedimento cirúrgico contribuindo para o aumento da probabilidade de ocorrência de complicações e infecções pós-cirúrgicas, bem como da taxa de mortalidade. Ademais, a resistência insulínica associada à uma ingestão menor de carboidratos também acarreta em um processo de cicatrização mais demorado. ${ }^{1}$

A sede intensa é outro sintoma desagradável ao paciente, tanto emocionalmente quanto fisiologicamente, este desconforto muitas vezes é até mais intenso que a dor e a fome sentidas. ${ }^{2,3}$ Alguns traços da sede intensa são a boca, lábios, garganta secas, saliva e língua grossa, sensação e gosto ruim na boca e necessidade de ingestão de líquidos. ${ }^{3}$ Quando a sede não é saciada contribui para o aumento da ansiedade, desespero e irritabilidade, bem como pode culminar em quadros de desidratação e fraqueza. Ainda mais, a sede é um dado subjetivo, sem mensuração palpável, o que leva à sua desvalorização ${ }^{2}$

Outra implicação de relevância para o prolongamento do jejum perioperatório é o aumento do estresse fisiológico. A resposta do organismo à um evento estressor consiste na cascata de eventos desencadeada pela ação de estímulos no hipotálamo e então no sistema nervoso simpático e medula supra-renal para ativar a liberação de substâncias responsáveis por desencadear outras cadeias de eventos com o intuito de manter o equilíbrio do organismo. Porém quando esses estímulos estão presentes em grandes quantidades, levam à uma resposta intensa e por tempo prolongado fazendo com que a resposta ao estresse fisiológico seja excessiva. ${ }^{5}$

Os manuscritos utilizados para a construção deste estudo apontam que o prolongamento do período de jejum perioperatório é uma prática comum em algumas instituições, independente de circunstâncias clínicas e que este período não segue o tempo recomendado pelos protocolos ${ }^{(3)}$. Sendo prejudicial ao paciente, pelo desconforto psicológico e fisiológico ocasionado pela sede intensa; assim como pelo dano ao metabolismo. Pesquisas evidenciam as complicações do jejum

\footnotetext{
${ }^{1}$ Acadêmica do sétimo período de Enfermagem na Universidade do Estado do Rio de Janeiro; bolsista do projeto de extensão da UERJ: Assistência de enfermagem no transoperatório ao acompanhante da criança em situação cirúrgica; voluntária de Iniciação Científica do projeto: Percepção dos acompanhantes das crianças quanto às orientações de enfermagem perioperatórias

${ }^{2}$ Acadêmica do sétimo período de Enfermagem na Universidade do Estado do Rio de Janeiro; bolsista de Iniciação Científica do projeto: Percepção dos acompanhantes das crianças quanto às orientações de enfermagem perioperatórias; voluntária do projeto de extensão. Assistência de enfermagem no transoperatório ao acompanhante da criança em situação cirúrgica

${ }^{3}$ Enfermeira. Doutora em Enfermagem. Docente da Faculdade de Enfermagem da Universidade do Estado do Rio de Janeiro. Departamento de Enfermagem Médico-Cirúrgica

${ }^{4}$ Enfermeiro. Doutor em Bioquímica. Professor Associado da Faculdade de Enfermagem da Universidade do Estado do Rio de Janeiro (UERJ). Departamento de Enfermagem Médico-Cirúrgica
} 
estendido para o paciente, logo, se faz necessário o questionamento da utilização deste período de forma generalizada, sem avaliação individual das variáveis clínicas do paciente. ${ }^{2,3}$

Ainda, é necessário que a aplicação do jejum perioperatório segundo métodos tradicionais inflexíveis seja revista, visto que já existem protocolos como o ACERTO, que busca uma rápida recuperação geral do paciente após o procedimento cirúrgico, bem como outras diretrizes à exemplo a American Society of Anaesthesiologists-ASA (Sociedade Americana de Anestesiologistas), Guideline - NNCG e Association of Anaesthetists of Great Britain and Ireland - AAGBI (Associação de Anestesistas da Grã-Bretanha e Irlanda) que baseiam-se no programa já existente Enhanced Recovery After Surgery- ERAS (Recuperação Aprimorada Após a Cirurgia). Esses protocolos têm em comum o incentivo à abreviação do período de jejum por meio da ingestão de líquidos claros, como água, café, sucos sem polpa, chá, bebidas carbonatadas e bebidas ricas em carboidratos até duas horas antes da cirurgia. Bem como, quatro horas para leite materno, seis horas para alimentação leve e não gordurosa e oito horas para alimentos gordurosos e sólidos. ${ }^{1,2}$

A revisão da utilização do período de jejum perioperatório tradicional, também deve ser pelo fato dos pacientes se manterem em jejum um tempo muito maior que o estabelecido devido à possíveis atrasos nas cirurgias, cancelamento das mesmas, transferências de horário e realização dos procedimentos, realização preferencial de cirurgias de emergência e demora da chegada da alimentação do paciente. ${ }^{1}$

Assim a enfermagem se faz extremamente relevante nesse momento, pois é necessário acolhimento psicológico, assistência individualizada, a fim de evitar um jejum prolongado, bem como, a oferta de cuidados para os sintomas advindos do período perioperatório. ${ }^{1}$

\section{REFERÊNCIAS}

(1) Sampaio CEP, de Carvalho ACR, Nassar PRB, de Souza MR. Percepção de enfermeiros quanto ao período de jejum pré-operatório. Revista Enfermagem Atual In Derme [Internet]. 2019 [cited 2021]:1-6.

Available from: https://www.researchgate.net/publication/341832809_Percepcao_de_enfermeiros_quanto_ao _periodo_de_jejum_pre-operatorio_Perception_of_nurses_about_preoperative_fasting

(2) da Silva LCJR, Aroni P, Fonseca LF. Tenho sede! Vivência do paciente cirúrgico no período perioperatório. Rev. SOBECC [Internet]. 2016 [cited 2021]:75-81. DOI 10.5327/Z14144425201600020003. Available from: https://docs.bvsalud.org/biblioref/2016/09/1662/sobeccv21n2_75-81_pt.pdf

(3) Pierotti I, Nakaya TG, Garcia AKA, Nascimento LA, Conchon MF, Fonseca LF. Avaliação do tempo de jejum e sede no paciente cirúrgico. Rev. baiana enferm. [Internet]. 2018 [cited 2021]; 32: e27679. Available from: http://www.revenf.bvs.br/scielo.php?script=sci_arttext\&pid=S2178$\underline{86502018000100364 \& \operatorname{lng}=p t .}$

(4) Martins AJC, Serva CAS, Fonseca TH, Martins MJL, Poveda VB. Jejum inferior a oito horas em cirurgias de urgência e emergência versus complicações. Rev Bras Enferm [Internet]. 2016 [cited 2017]; 69(4):712-7. Available from: http://www.scie-lo.br/pdf/reben/v69n4/0034-7167reben-69-04-0712.pdf.

(5) Ludwig RB, Paludo J, Fernandes D, Scherer F. Menor tempo de jejum pré-operatório e alimentação precoce no pós-operatório são seguros? ABCD. Arq Bras Cir Dig. 2013[cited 2017]; 26(1):54-58. Available from: http://www.scielo.br/pdf/abcd/v26n1/12.pdf 